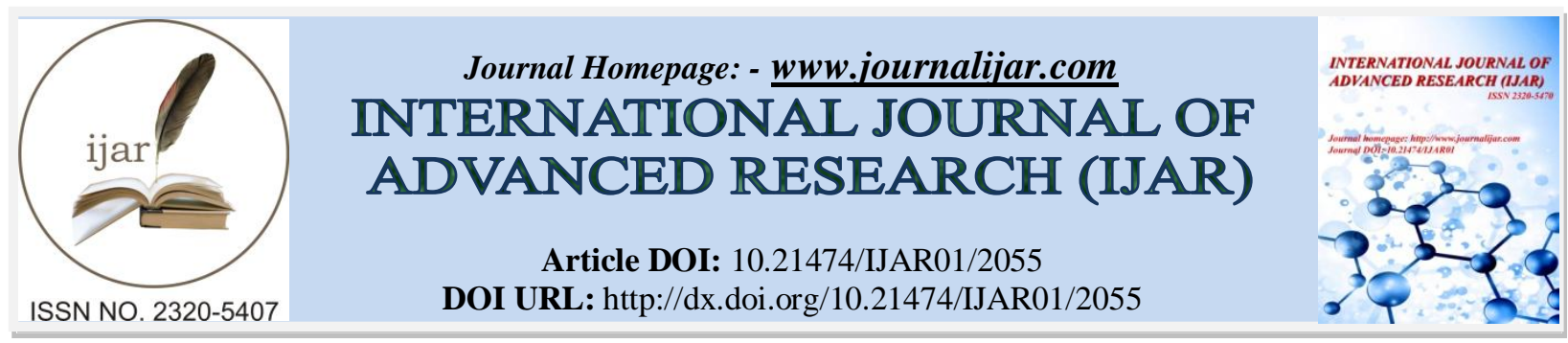

RESEARCH ARTICLE

\title{
MOLECULAR DETECTION OF GYRA AND PARC GENES IN MULTIDRUG RESISTANT ACINETOBACTER BAUMANNII ISOLATED FROM NOSOCOMIAL INFECTIONS IN CHILDREN.
}

Ban Imad Abbood ${ }^{1}$ and Dr. Falah Salim Manhal ${ }^{2}$.

1. M Sc student, Children Welfare Teaching Hospital, Medical City, Baghdad, Iraq.

2. PhD Medical Microbiology, Middle Technical University, College of Health \& Medical Technology, Dept. of Medical Laboratory Technology, Baghdad, Iraq.

\section{Manuscript Info}

(.........................

Manuscript History

Received: 20 September 2016

Final Accepted: 22 October 2016

Published: November 2016

Key words:-

A. baumannii, multi-drug-resistant, gyrA and $\operatorname{parC}$

\section{Abstract}

This study was conducted in Children Welfare Teaching Hospital, Baghdad, Iraq in order to detect gyrA and parC genes in multidrug resistant Acinetobacter baumannii isolated from nosocomial infections in children. A total of 50 child patients were selected according to study criteria. Different specimens obtained from child patients and hospital environment were tested by culture and antimicrobial sensitivity according to standard bacteriological and molecular techniques. Blood stream infections comprised the highest number and percentages within suspected nosocomial infections, 21 (42\%) of paediatric patients were detected with early onset sepsis (EOS), and $19(38 \%)$ were with late onset sepsis (LOS). Forty A. baumannii isolates were identified at species level by using VITEK ${ }^{\circledR} 2$ Compact and $16 s$ rRNA. Oligonucleotide primers sequences were used for PCR amplification of $16 s \quad r R N A, g y r A$ and parC of Acinetobacter baumannii. All of $A$. baumannii isolates were multidrug resistant (MDR) pathogens. Resistance gyrA and parC genes were detected in $58 \%$ and $100 \%$ of study isolates, respectively. Nosocomial sepsis in neonates were still at high-frequency in child patients. The vast majority of $A$. baumannii isolates were multidrug resistant and harboring gyrA and parC resistance genes. Considerable efforts are needed for choosing antimicrobial drugs and combination therapy. Further studies are required for genotyping by sequencing of problematic resistant $A$. baumannii isolates in our hospitals.

Copy Right, IJAR, 2016,. All rights reserved.

\section{Introduction:-}

Acinetobacter baumannii (A. baumannii) is a major cause of nosocomial infections due to its ability to survive on dried surfaces favored by constant usage of antibiotics in hospital setting [1]. Emergence of environmentally selected clones with characteristic antimicrobial resistance has been detected worldwide [2]. The primary reservoir of Acinetobacter species in which these bacteria can live and multiply involves water, soil, and skin of healthy individuals including hospital staff [3]. In contrast to other Acinetobacter species, A. baumannii is predominantly

Corresponding Author:- Falah Salim Manhal.

Technology, Dept. of Medical Laboratory Technology, Baghdad, Iraq. 
detected in hospital setting, although it may be occasionally isolated from environmental soil and water specimens. Multidrug-resistant Acinetobacter baumannii (MDRAB) is constantly detected in certain hospital departments which are difficult to control [4]. Immunocompromised patients in intensive care units, neonatal units, and surgical wards are more frequently subjected to such infections [5]. Community-acquired infections caused by A. baumannii have also been recorded by some reports in patients with critical underlying illnesses especially in tropical or sub-tropical areas [6]. Acinetobacter infections are gaining a lot of concern as potential pathogens in neonatal hospital-acquired infections have been documented by different research studies [5].

The antibiotic resistance in Acinetobacter species is inherent and naturally acquired especially against aminoglycosides, chloramphenicol, and penicillin. Some reports have also recorded fluoroquinolones resistance in these pathogens which have also developed resistance to other antibiotic classes [7]. The previous studies concerned with A. baumannii infection were almost focusing on antibiotic resistance and control measurements, however, scarce information were provided regarding investigations of virulence of these pathogens [8]. Factors that pay attentions toward the study of virulence factors of A. baumannii have been facilitated by admission of molecular techniques for the completion of genomic sequences and experimental infections in lab animals. Consequently, researchers have found their scientific approach to disclose and confirm molecular characteristics of $A$. baumannii which may determine its pathological importance in disease production. These characteristics, as shown in many pathogens, confer them virulence factors and resistance abilities. Pathogenicity AbaR resistance islands, the betalactamase OXA-23, biofilm formation, capsule production, efflux pumps, small RNAs, and adhesion molecules are some of the well studied properties which grant A. baumannii genome plasticity and to be successful pathogens [9].

DNA gyrase and topoisomerase IV enzymes are essential component of bacterial repair system during DNA replication and transcription. These enzymes consist of multiple subunits, each are encoded by their own genes. The most thoroughly studied genes in bacteria are $\operatorname{gyr} A$ and $\operatorname{parC}$ genes, respectively. These enzymes may be targeted by certain antibiotic agents [10]. However, antibiotic-resistant $A$. baumannii most commonly have mutations in gyrA and $\operatorname{par} C$ genes especially with quinolone therapy. It was found that the synchronous mutations in the quinolone resistance determining region (QRDR) of the gyrA and parC genes may result in significant fluoroquinolones resistance in A. baumannii isolates [11].

In Iraq, A. baumannii have gained much importance especially after the American occupation of this country in 2003 when it was named 'Iraqibacter'. It has been detected in a number of wound infections in soldiers who served in Iraq during the war, and has continued to be an issue among the medical researchers of US army. Before this time, Pseudomonas aeruginosa was known as the most frequently isolated microbe from wound and burn specimens in Iraqi hospitals. Nevertheless, A. baumannii infections may be either underestimated or misdiagnosed in hospital setting. Recently, a lot of study research have been conducted in Iraq focusing on investigation of virulence factors in this pathogen, but rare information has been provided regarding the molecular aspects of nosocomial infections in children, especially neonates. Studies dealing with distribution of antibiotic resistance genes play an important role in treatment and prevention strategies for nosocomial infection. Hence, the objective of our study was to record association between gyrA and parC genes of A. baumannii in clinical isolates and antibiotic resistance in a group of hospitalized Iraqi children.

\section{Patients and methods:-}

This study was conducted at Children Welfare Teaching Hospital in Baghdad Medical City, Baghdad from September 2015 to March 2016. The hospital has 497 beds offering various medical services in multiple departments which include: Neonatal Intensive Care Unit, Respiratory Care Unit, Gastrointestinal Tract, Nephrology, Endocrinology, Oncology, and Hematology Departments. Fifty paediatric patients were selected according to their clinical history of having infection, either preterm or nosocomially acquired. Age group of children enrolled in this study was from one day to 12 years. Children were admitted in the hospital departments for different medical interventions and pediatric welfare services. Paediatric patients with nosocomial infections were selected according to the criteria of Centers for Disease Control and Prevention/National Nosocomial Infections Surveillance (CDC-NNIS) System [12]. These criteria stress on clinical history as having fever (Temperature $>38$ ${ }^{\circ} \mathrm{C}$ ), leukocytosis, and positive bacterial culture after the third day of hospitalization. Neonatal infections were categorized as; early onset infections that were presented during the first three days of life, and late onset that were hospital-acquired infections after the first week of life. Early onset infections are transplacentally acquired from mothers. [13]. 


\section{Collection of specimens:-}

Fifty clinical samples were collected from study patients that involved: blood, cerebrospinal fluid, ascitic fluid, throat swabs, wound swabs, and urine. In addition, fifty hospital environment specimens were also collected from different hospital locations that involved: medical and surgical equipment, beds, walls, floors, bathrooms, and kitchens. Sterile swabs were used to test the level of microbial contamination on various surfaces of the hospital. In order to avoid drying of specimens, swabs were transported to the laboratory in a sealed zip lock bag. Unlabelled, leaking, too old ( $>24$ hours) specimens were rejected. Transportation of specimens to the laboratory for processing was attempted as soon as possible in a time not exceeded an average of 2 hours.

\section{Isolation and Identification of bacterial isolates:-}

All these specimens were subjected to cultural methods and antimicrobial sensitivity tests according to standard bacteriological procedures [14]. Blood, Chocolate, and MacConkey agar plates (Biomark/India) were inoculated and then incubated aerobically at $35^{\circ} \mathrm{C}$ for a maximum of 48 hours. Bacterial growth was monitored and graded as scanty, light, moderate, or heavy according to colony morphology appearance. Gram staining, motility, oxidase, catalase, fermentative/oxidative tests were also done according to bacteriological standards.

Identification of A. baumannii isolates was confirmed by API 20NE and VITEK 2 compact card for Gram-negative bacteria (BioMerieux, France) according to manufacturer's instructions. Antibiotic sensitivity tests were performed by manual Kirby-Bauer disk diffusion and automated broth microdilution (VITEK 2 compact, BioMerieux, France). The agar diffusion method was done by using Mueller-Hinton agar (Biomark / India) on which antimicrobial disks were placed and incubated overnight at $35^{\circ} \mathrm{C}$. Different antibiotic disks (Becton, Dickinson) were used, that's including: Ampicillin (10 mcg), Amoxicillin/ Clavulanic acid $(20 / 10 \mathrm{mcg})$, Ampicillin/sulbactam (10/10 mcg), Piperacillin/tazobactam (100/10 mcg), Cefazolin (30 mcg), Ceftazidime (30 mcg), Ceftriaxone (30 mcg), Impeneme $(10 \mathrm{mcg})$, Gentamycin $(10 \mathrm{mcg})$, Tobramycin $(10 \mathrm{mcg})$, Ciprofloxacin $(5 \mathrm{mcg})$, and Levofloxacin $(5 \mathrm{mcg})$. The minimum inhibitory concentrations (MIC) of all selected antimicrobial agents against the A. baumannii strains were determined by VITEK 2 compact system. The MIC was defined as the lowest concentration of the antimicrobial agent that determined with a notified alteration in the growth of bacterial isolates. The results were interpreted according Clinical and Laboratory Standards Institute (CLSI) Guidelines [15].

\section{Molecular detection of Acinetobacter genes:-}

Bacterial culture was inoculated in $5 \mathrm{ml}$ brain heart broth (Biomark/India) and incubated for $24 \mathrm{hrs}$ at $37 \mathrm{C}^{\circ}$. Cultural methods were used to detected the purity of isolates without contamination, and then DNA extraction procedure was performed according to standard techniques.

\section{DNA extraction protocol:-}

DNA extraction kit (G- spin Intron / Korea) was used for total DNA extraction of bacterial isolates according to manufacturer's protocol. Briefly, the bacterial lysate was prepared by adding lysis buffer, protienase K, and RNase solutions into the bacterial pellet. After several processing steps, the mixture was carefully applied to the Spin Column followed by a multiple steps of centrifugation. Measuring of DNA absorbance was attempted at $260 \mathrm{~nm}$ and $280 \mathrm{~nm}$ for the determination of purity and concentration of extracted bacterial DNA by using Nano drop spectrophotometer (BioNeer / Korea). Finally, 2\% agarose gel electrophoresis (Laboratorios CONDA, Spain) was performed in order to affirm the integrity of the extracted DNA.

\section{Preparing the primers:-}

Oligonucleotide primers (Alpha DNA, Canada) were received in a lyophilized form and dissolved with a sterile deionized water. A stock and working solutions were prepared and stored at $-20 \mathrm{C}^{\circ}$ until used. The following table shows oligonucleotide primers sequences of $16 s \mathrm{r} R N A$, gyrA and parC of $A$. baumannii which have been used for PCR amplification. 
Table 1:- Oligonucleotide primers sequences of $16 s \mathrm{rRNA}, \operatorname{gyr} A$ and $\operatorname{parC}$ of $A$. baumannii.

\begin{tabular}{|c|c|c|c|}
\hline Target gene & \begin{tabular}{|c|} 
Primers sequences \\
\end{tabular} & Product size & Reference \\
\hline \multirow{2}{*}{$16 s$ rRNA } & Forward: 5'AGAGTTTGATCCTGGCTCAG-'3 & \multirow{2}{*}{$\begin{array}{c}750 \\
\text { base pair }\end{array}$} & \multirow{2}{*}{$\begin{array}{l}\text { Shipra Srivastava } \\
\text { et al.[16] }\end{array}$} \\
\hline & $\begin{array}{l}\text { Reverse: } \\
\text { 5' TACCAGGGTATCTAATCCTGTT-'3 }\end{array}$ & & \\
\hline \multirow[t]{2}{*}{ gyrA } & $\begin{array}{l}\text { Forward: } \\
\text { AAATCTGCTCGTGTCGTTGG-'3 }\end{array}$ & \multirow[t]{2}{*}{$\begin{array}{c}349 \\
\text { base pair }\end{array}$} & \multirow[t]{2}{*}{$\begin{array}{c}\text { Jordi Vila et al. } \\
\text { [17] }\end{array}$} \\
\hline & $\begin{array}{l}\text { Reverse: } \\
\text { 5'- GCCATACCTACAGCAATACC-'3 }\end{array}$ & & \\
\hline \multirow[t]{2}{*}{ parC } & $\begin{array}{l}\text { Forward: } \\
\text { AAGCCCGTACAGCGCCGTATT-'3 }\end{array}$ & \multirow[t]{2}{*}{$\begin{array}{c}327 \\
\text { base pair }\end{array}$} & \multirow{2}{*}{$\begin{array}{c}\text { Mohammad- } \\
\text { Hossein Maleki et } \\
\text { al, [18] }\end{array}$} \\
\hline & $\begin{array}{l}\text { Reverse: } \\
\text { 5'- AAAGTTATCTTGCCATTCGCT-'3 }\end{array}$ & & \\
\hline
\end{tabular}

\section{PCR amplification:-}

For each study primer, the following mixtures were adopted in PCR analysis: Taq PCR PreMix (Maxime PCR PreMix Kit $i$-Taq, Intron/Korea) $5 \mu$, Forward primer $1 \mu$ l, Reverse primer $1 \mu$ l, DNA extract $1.5 \mu$ l, and Distill water $16.5 \mu \mathrm{l}$ to reach the final volume of $25 \mu \mathrm{l}$. Amplification was included in every set of PCR reactions by using MultiGene OptiMax Gradient Thermal Cycler Labnet, USA. The optimum conditions for detection of 16s rRNA, gyrA, and $\operatorname{parC}$ genes were initiated by denaturation at $94{ }^{\circ} \mathrm{C}$ for $3 \mathrm{~min}$, followed by 35 cycle of denaturation at 94 ${ }^{\circ} \mathrm{C}$ for $1 \mathrm{sec}$, annealing at $59{ }^{\circ} \mathrm{C}$, for $1 \mathrm{sec}$, extension- 1 at $72{ }^{\circ} \mathrm{C}$ for $1 \mathrm{sec}$, and extension- 2 at $72{ }^{\circ} \mathrm{C}$ for $7 \mathrm{~min}$. The products of PCR reaction cycles were separated by using $2.25 \%$ agarose gel electrophoresis (Laboratorios CONDA, Spain). Visualization of PCR products was attempted by staining with nucleic acid staining solution (RedSafe ${ }^{\mathrm{TM}}$ Intron, Korea) and completed under ultraviolet exposure.

\section{Statistical analysis:-}

Statistical analysis was performed by using Statistical Package for Social Sciences (SPSS) software version-17.0 (SPSS, Inc., Chicago, IL, USA). Categorical variables were presented as numbers and percentages for descriptive statistics. Mean and standard deviation was used to describe age; number and percentage were used to describe VITEK2, gyrA, parC genes and antibiotics.

\section{Results:-}

A total of 50 paediatric patients were selected according to study criteria. Age of all patients were up to 12 years. Male patients were $27(54 \%)$, whereas female patients were $23(46 \%)$. Patients were diagnosed with various nosocomial infections that's included: blood stream infections, bacterial meningitis, urinary tract infections, wound infections, upper respiratory tract infection, and peritonitis. Distribution of study patients according to age group is shown on table 2. Majority of children were in age group of less than one year, $40(80 \%)$.

Table 2:- Distribution of study patients according to age groups.

\begin{tabular}{|l|c|c|}
\hline \multicolumn{1}{|c|}{ Age group } & No. of children & \% \\
\hline Less than one year & 40 & $80 \%$ \\
\hline $1-5$ year & 7 & $14 \%$ \\
\hline More than 5 years & 3 & $6 \%$ \\
\hline Total & 50 & $100 \%$ \\
\hline
\end{tabular}

Table 3 shows frequency of nosocomial infections in study patients. Blood stream infections comprised the highest number and percentages within suspected nosocomial and early onset neonatal infections 40 (80\%). It was found that $21(42 \%)$ children were infected with early onset sepsis whereas late onset sepsis was found in 19 patients. The other patients were infected with bacterial meningitis $3(6 \%)$, urinary tract infections $3(6 \%)$, wound infections 2 $(4 \%)$. Peritonitis and upper respiratory tract infections comprised the least number and percentage, only one case (2\%) for each. 
Table 3:- Frequency of nosocomial infections in study patients.

\begin{tabular}{|c|c|c|c|}
\hline \multicolumn{2}{|c|}{ Nosocomial infections } & No. of children & $\%$ \\
\hline \multirow[t]{2}{*}{ Blood stream infection } & EOS* & 21 & $42 \%$ \\
\hline & LOS** & 19 & $38 \%$ \\
\hline Bacterial meningitis & & 3 & $6 \%$ \\
\hline Urinary tract infections & & 3 & $6 \%$ \\
\hline Wound infections & & 2 & $4 \%$ \\
\hline Upper respiratory tract infections & & 1 & $2 \%$ \\
\hline Peritonitis & & 1 & $2 \%$ \\
\hline Total & & 50 & $100 \%$ \\
\hline
\end{tabular}

* Early onset sepsis (EOS) detected within one week of age

** Late onset sepsis (LOS) detected at age more than one week

A. baumannii isolates were diagnosed and identified according to their morphological, biochemical, and molecular characteristics. Phenotypic characterization alone did not discriminate Acinetobacter isolates from each other. Consequently, molecular detection of 16SrRNA was adopted for the accurate identification of A. baumannii at species level. The isolated bacteria were Gram negative aerobic, non-fermentative and nonmotile bacilli. Biochemical reactions revealed negative oxidase and positive catalase activity.

A total of $40(80 \%)$ bacterial isolates were identified as Acinetobacter spp in clinical specimens according to traditional culture procedures. It was found that $20(40 \%)$ isolates of A. baumannii were detected in blood specimens of children suspected with blood stream infection according to VITEK2 system and 16SrRNA. Other isolates included two (4\%) isolates in CSF, one isolate (2\%) in throat swab and urine for each. Only two (4\%) A. baumannii isolates were detected in the fifty hospital environmental specimens, one (2\%) in ventilator swab and the other in anesthesia mask swab. Other organism detected were 2 (4\%) Staphylococcus epidermdis isolates. The remaining environmental specimens showed no growth.

All of A. baumannii isolates (100\%) were considered as multi-drug-resistant (MDR) pathogens because they were resistant to multiple antibiotic therapies. MDR was defined as acquired antibiotic insensitivity to at least one drug within three or more antimicrobial classes [19]. The higher antibiotic sensitivity was observed with Ampicillin/Sulbactam, Imipenem, and Levofloxacin in $12(30 \%)$ of bacterial isolates.

Table 4 shows frequency of $A$. baumannii isolates which harbor gyrA and parC genes associated with antibiotic resistance to different agents. It was found that $58 \%$ of study isolates harbor gyrA antibiotic resistance gene to different antibiotic agents. On the other hand, all study isolates (100\%) were found to have parC antibiotic resistance gene. Figures 1, 2, and 3 show these genes by gel electrophoresis under UV light visualization.

Table 4:- Association between gyrA gene and parC with antibiotic resistance of $A$. baumannii isolates.

\begin{tabular}{|c|c|c|c|c|c|c|c|c|c|}
\hline & \multicolumn{4}{|c|}{ gyrA gene } & \multicolumn{4}{|c|}{ parC gene } \\
\hline & & \multicolumn{2}{|c|}{ Positive } & \multicolumn{2}{|c|}{ Negative } & \multicolumn{2}{|c|}{ Positive } & \multicolumn{2}{|c|}{ Negative } \\
\hline & & No. & $\%$ & No. & $\%$ & No. & $\%$ & No. & $\%$ \\
\hline \multirow[t]{3}{*}{ Ampicillin/ Sulbactam } & $\mathrm{S}$ & 8 & $20 \%$ & 4 & $10 \%$ & 12 & $30 \%$ & 0 & $.0 \%$ \\
\hline & I & 1 & $2.5 \%$ & 0 & $.0 \%$ & 1 & $2.5 \%$ & 0 & $.0 \%$ \\
\hline & $\mathrm{R}$ & 21 & $52 \%$ & 6 & $15 \%$ & 27 & $67.5 \%$ & 0 & $.0 \%$ \\
\hline \multirow[t]{3}{*}{ Piperacillin/ Tazobactam } & $\mathrm{S}$ & 8 & $20 \%$ & 3 & $7.5 \%$ & 11 & $27.5 \%$ & 0 & $.0 \%$ \\
\hline & I & 0 & $.0 \%$ & 0 & $.0 \%$ & 0 & $.0 \%$ & 0 & $.0 \%$ \\
\hline & $\mathrm{R}$ & 22 & $55 \%$ & 7 & $17.5 \%$ & 29 & $72.5 \%$ & 0 & $.0 \%$ \\
\hline \multirow[t]{3}{*}{ Cefazolin } & $\mathrm{S}$ & 0 & $.0 \%$ & 0 & $.0 \%$ & 0 & $.0 \%$ & 0 & $.0 \%$ \\
\hline & I & 0 & $.0 \%$ & 0 & $.0 \%$ & 0 & $.0 \%$ & 0 & $.0 \%$ \\
\hline & $\mathrm{R}$ & 30 & $75.0 \%$ & 10 & $25.0 \%$ & 40 & $100.0 \%$ & 0 & $.0 \%$ \\
\hline \multirow[t]{3}{*}{ Ceftazidime } & $\mathrm{S}$ & 5 & $12.5 \%$ & 2 & $5 \%$ & 7 & $17.5 \%$ & 0 & $.0 \%$ \\
\hline & I & 1 & $2.5 \%$ & 1 & $2.5 \%$ & 2 & $5 \%$ & 0 & $.0 \%$ \\
\hline & $\mathrm{R}$ & 24 & $60 \%$ & 7 & $17.5 \%$ & 31 & $77.5 \%$ & 0 & $.0 \%$ \\
\hline \multirow[t]{3}{*}{ Ceftriaxone } & $\mathrm{S}$ & 2 & $5 \%$ & 0 & $.0 \%$ & 2 & $5 \%$ & 0 & $.0 \%$ \\
\hline & $\mathrm{I}$ & 4 & $10 \%$ & 3 & $7.5 \%$ & 7 & $17.5 \%$ & 0 & $.0 \%$ \\
\hline & $\mathrm{R}$ & 24 & $60 \%$ & 7 & $17.5 \%$ & 31 & $77.5 \%$ & 0 & $.0 \%$ \\
\hline
\end{tabular}




\begin{tabular}{|c|c|c|c|c|c|c|c|c|c|}
\hline \multirow[t]{3}{*}{ Imipenem } & $\mathrm{S}$ & 8 & $20 \%$ & 4 & $10 \%$ & 12 & $30 \%$ & 0 & $.0 \%$ \\
\hline & I & 6 & $15 \%$ & 3 & $7.5 \%$ & 9 & $22.5 \%$ & 0 & $.0 \%$ \\
\hline & $\mathrm{R}$ & 16 & $40 \%$ & 3 & $7.5 \%$ & 19 & $47.5 \%$ & 0 & $.0 \%$ \\
\hline \multirow[t]{3}{*}{ Gentamicin } & $\mathrm{S}$ & 7 & $17.5 \%$ & 3 & $7.5 \%$ & 10 & $25 \%$ & 0 & $.0 \%$ \\
\hline & I & 0 & $.0 \%$ & 0 & $.0 \%$ & 0 & $.0 \%$ & 0 & $.0 \%$ \\
\hline & $\mathrm{R}$ & 23 & $57.5 \%$ & 7 & $17.5 \%$ & 30 & $75 \%$ & 0 & $.0 \%$ \\
\hline \multirow[t]{3}{*}{ Tobramycin } & $\mathrm{S}$ & 8 & $20 \%$ & 3 & $7.5 \%$ & 11 & $27.5 \%$ & 0 & $.0 \%$ \\
\hline & I & 10 & $25 \%$ & 2 & $5 \%$ & 12 & $30 \%$ & 0 & $.0 \%$ \\
\hline & $\mathrm{R}$ & 12 & $30 \%$ & 5 & $12.5 \%$ & 17 & $42.5 \%$ & 0 & $.0 \%$ \\
\hline \multirow[t]{3}{*}{ Ciprofloxacin } & $\mathrm{S}$ & 8 & $20 \%$ & 3 & $7.5 \%$ & 11 & $27.5 \%$ & 0 & $.0 \%$ \\
\hline & I & 1 & $2.5 \%$ & 0 & $.0 \%$ & 1 & $2.5 \%$ & 0 & $.0 \%$ \\
\hline & $\mathrm{R}$ & 21 & $52.5 \%$ & 7 & $17.5 \%$ & 28 & $70 \%$ & 0 & $.0 \%$ \\
\hline \multirow[t]{3}{*}{ Levofloxacin } & $\mathrm{S}$ & 9 & $22.5 \%$ & 3 & $7.5 \%$ & 12 & $30 \%$ & 0 & $.0 \%$ \\
\hline & I & 0 & $.0 \%$ & 0 & $.0 \%$ & 0 & $.0 \%$ & 0 & $.0 \%$ \\
\hline & $\mathrm{R}$ & 21 & $52.5 \%$ & 7 & $7.5 \%$ & 28 & $70 \%$ & 0 & $.0 \%$ \\
\hline \multirow[t]{3}{*}{ Nitrofurantoin } & $\mathrm{S}$ & 0 & $.0 \%$ & 0 & $.0 \%$ & 0 & $.0 \%$ & 0 & $.0 \%$ \\
\hline & I & 0 & $.0 \%$ & 0 & $.0 \%$ & 0 & $.0 \%$ & 0 & $.0 \%$ \\
\hline & $\mathrm{R}$ & 30 & $75.0 \%$ & 10 & $25.0 \%$ & 40 & $100.0 \%$ & 0 & $.0 \%$ \\
\hline \multirow{3}{*}{$\begin{array}{l}\text { Trimethoprim/ } \\
\text { Sulfamethoxazole }\end{array}$} & $\mathrm{S}$ & 8 & $20 \%$ & 3 & $7.5 \%$ & 11 & $27.5 \%$ & 0 & $.0 \%$ \\
\hline & I & 0 & $.0 \%$ & 0 & $.0 \%$ & 0 & $.0 \%$ & 0 & $.0 \%$ \\
\hline & $\mathrm{R}$ & 22 & $55 \%$ & 7 & $17.5 \%$ & 29 & $72.5 \%$ & 0 & $.0 \%$ \\
\hline
\end{tabular}

$* \mathbf{S}=$ Sensitive, I= Intermediate, $\mathbf{R}=$ Resistant

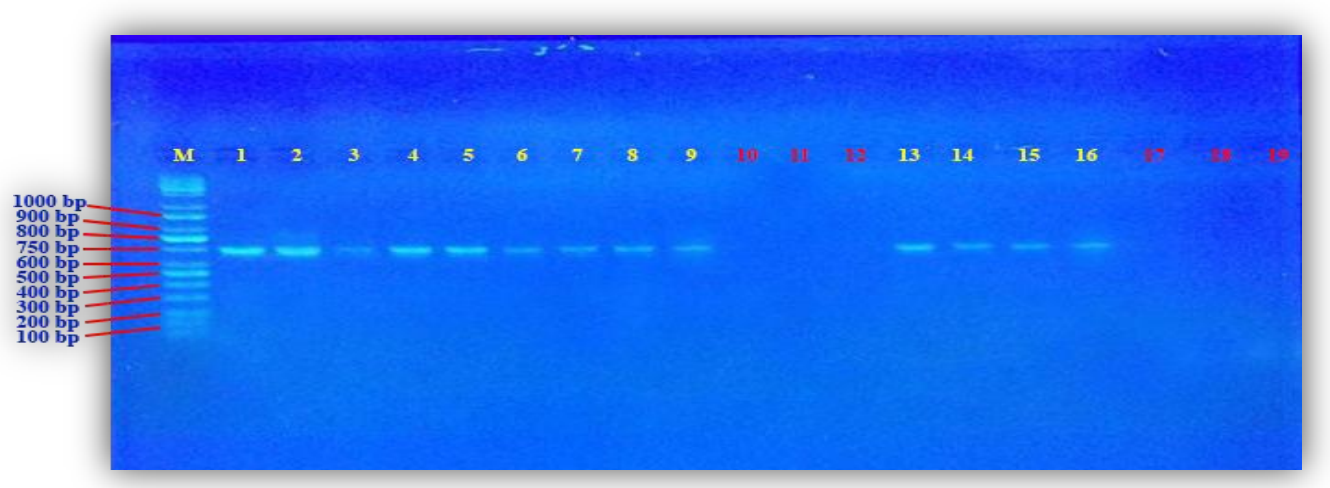

Figure 1:- Visualization of $16 \mathrm{~S}$ rRNA gene with $750 \mathrm{bp}$ by gel electrophoresis $(2.25 \%$ agarose, $5 \mathrm{volt} / \mathrm{cm} 2)$ under UV light. Line M: 100bp ladder. Line $(1,2,3,4,5,6,7,8,9,13,14,15,16)$ represent positive results, while line $(10,11,12,17,18,19)$ show negative results.

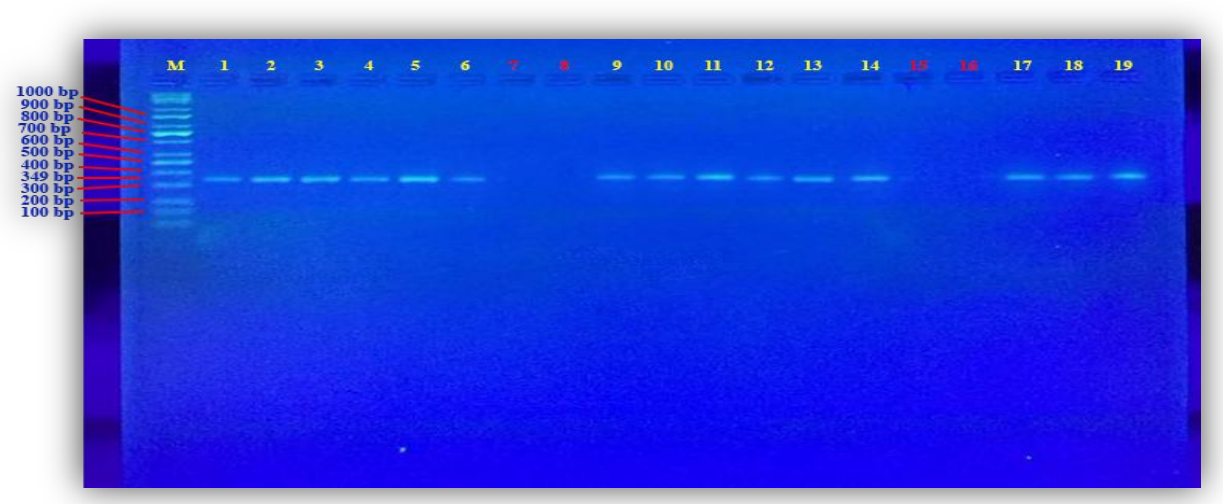

Figure 2:- Visualization of gyrA gene with 349 bp by gel electrophoresis $(2.25 \%$ agarose, 5 volt $/ \mathrm{cm} 2)$ under UV light. Line M: 100bp ladder. Line $(1,2,3,4,5,6,9,10,11,12,13,14,17,18,19)$ represent positive results while line $(7,8,15,16)$ show negative results . 


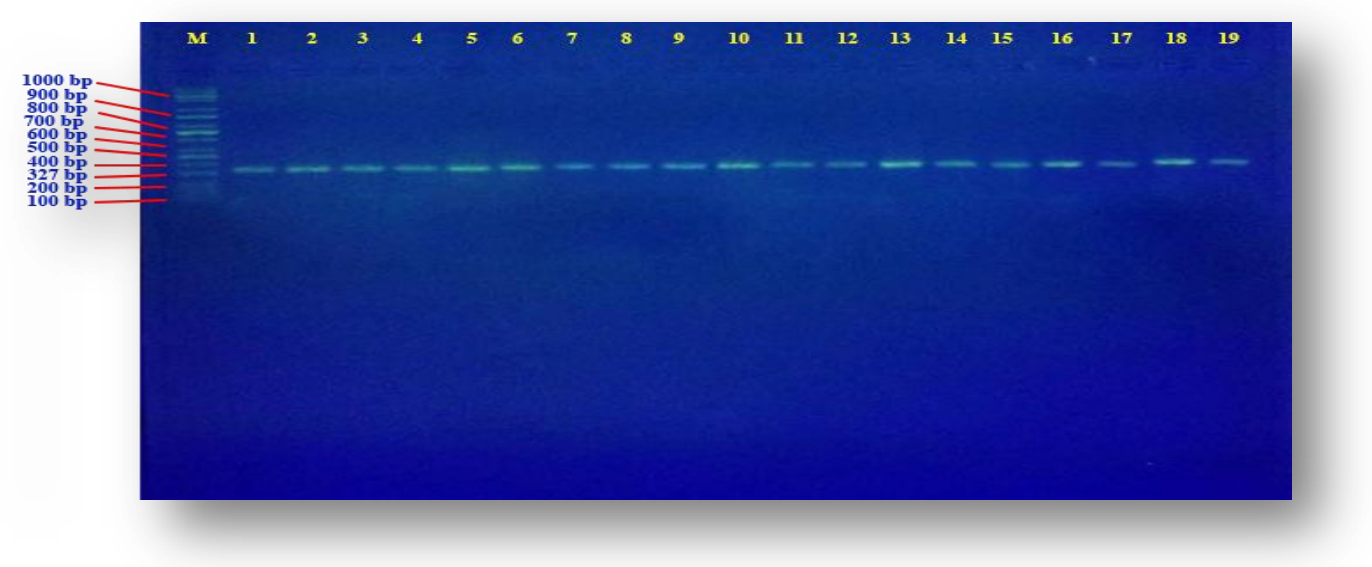

Figure 3:- Visualization of $16 \mathrm{~S}$ rRNA gene with 327 by gel electrophoresis $(2.25 \%$ agarose, 5 volt/cm2) under UV light. Line M: 100bp ladder. Line $(1,2,3,4,5,6,7,8,9,10,11,12,13,14,15,16,17,18,19)$ represent positive results.

\section{Discussion:-}

Different types of nosocomial infections are frequently observed in hospitalized children depending on certain factors such as age of children, hospital department, and medical instruments used. In our study, majority of patients were in age group of less than one year, $40(80 \%)$, with high frequency of blood stream infections. Prevalence of neonatal sepsis in Children Welfare Teaching Hospital, Baghdad, Iraq obtained from hospital records was $21 \%$ (from 2800 tested blood specimens) during the period from January to June 2016. About 50\% of bacterial isolates of these infections were caused by Streptococcus spp. and 30\% were caused by Acinetobacter spp. According to hospital records, the mortality rate due to sepsis in preterm neonates was $2 \%$. In our study, only three $(6 \%)$ infants died. Our results were relatively in accordance with other studies, particularly in developing countries, where the newborns are more susceptible to nosocomial infections within pediatric groups. Several factors were implicated such as lack of resources and poor health care facilities [21]. Our study indicated that 21 (42\%) children had early onset sepsis (EOS), the result that was in agreement with other studies. Maternal factors and premature delivery were shown to be the preliminary risk factors for acquiring sepsis in neonates [22]. On the other hand, the frequency of hospital-acquired sepsis in our study was estimated as $38 \%$, a problem that remains a major concern in health care provided in developing countries.

The culture results of our study indicated that $20(40 \%)$ isolates of $A$. baumannii were detected in children suspected with blood stream infection. All of these isolates (100\%) were multi-drug-resistant (MDR) microbes. Blood stream infections and septicemia caused by MDR A. baumannii have been recorded worldwide with high morbidity and mortality rates [20]. Whereas many research studies have shed light on the worldwide emergence of Acinetobacter spp. threat, there are relatively few, if any, reports which have dealt with this issue in Iraqi hospitals. Previously, nosocomial infections in Iraq were most frequently diagnosed as Pseudomonas infections. Probably, many species of Gram negative non-fermentative rods other than Pseudomonas were misdiagnosed or not identified due to lacking of sophisticated laboratory techniques.

Regarding hospital environmental specimens, it was found that only two (4\%) of A. baumannii isolates were detected. The hospital survey records indicated $7 \%$ contamination rate by A. baumannii during the period of our study. The other species isolates were: Staph epidermdis (63\%), Pseudomonas spp (13\%), Bacillus spp (13\%), Pantoea spp (2\%), and Enterococcus spp (2\%) [data not shown]. High contamination rates may be due to unawareness of health care workers of the high risk for contamination, or they may contaminate their clothing and skins while taking off their lab coats and gloves.

High rate of antibiotic resistance was detected in our study, namely $100 \%$ to Ampicillin, Augmentin, and Cefazolin, probably due to antibiotic misuse or overuse in treatment of bacterial infections. The MIC values of strains harboring gyrA and parC resistance genes particularly in resistance to quinolones (Ciprofloxacin and Levofloxacin) showed $52.5 \%$ resistance rate. These isolates were detected with higher MIC values ( $\geq 35 \mu \mathrm{g} / \mathrm{ml})$ to ciprofloxacin and Levofloxacin than other agents. According to CLSI breakpoints and clinical judgment, MIC interpretive 
standards for Quinolones in A. baumannii isolates were undertaken as: $(\mathrm{S} \leq 1, \mathrm{I}=2, \mathrm{R} \geq 4$ for Ciprofloxacin) and ( $\mathrm{S} \leq 2$, $\mathrm{I}=4, \mathrm{R} \geq 8$ for Levofloxacin).

The present study recorded high carriage rate of resistance genes, gyrA and parC in A. baumannii nosocomial infections. Mutation occurring in these genes were recorded by multiple studies, making these bacteria more virulent and resistant to different classes of antimicrobial agents. The situation is more complicated with A. baumannii which are frequently implicated in causing outbreaks especially in intensive care units and immunocompromised patients such as preterm and neonates [23]. To the best of our knowledge, this is the first study to detect $g y r A$ and parC genes in $A$. baumannii causing nosocomial infections in a group of Iraqi children. In an Iranian study conducted by Jamileh Nowroozi et al, it was found that frequency of Acinetobacter resistance to Ciprofloxacin was $100 \%$ in $A$. baumannii isolates, and the MIC of Ciprofloxacin in all (100\%) of isolates was 32-64 $\mu \mathrm{g} / \mathrm{mL}$. In $100 \%$ of the isolates parC and gyrA genes bands were detected, [24]. In a Turkish study conducted by Güler G et al, it was found that $\mathrm{MIC}(50)$ and $\mathrm{MIC}(90)$ values for CIP were $256 \mu \mathrm{g} / \mathrm{ml}$ and $\geq 256 \mu \mathrm{g} / \mathrm{ml}$, while the values were $32 \mu \mathrm{g} / \mathrm{ml}$ and $128 \mu \mathrm{g} / \mathrm{ml}$ for LEV, respectively. Overall, Ciprofloxacin MIC values were found to be higher than that of Levofloxacin among the A. baumannii strains studied. According to the conclusion of the Turkish study, the high fluoroquinolone MIC values of $A$. baumannii isolates were associated with target mutations in gyrA and parC genes [25]. A previously conducted surveillance study in Korea in 2009 observed 67\% resistance rate of Acinetobacter spp. to fluoroquinolone conferred by gyrA and parC sense mutations [26]. In a study conducted by Wayne A. Warner et al of A. baumannii isolates obtained from two hospital outbreaks in Los Angeles County, California, USA it was shown that all isolates were resistant to Ciprofloxacin and Levofloxacin in correlation with point mutation in gyrA and parC genes. The MIC range, $\mathrm{MIC}_{50}$ and $\mathrm{MIC}_{90}$ observed in the American study was (64-128, 128, and 128 for Ciprofloxacin, respectively) and (16-64, 32, and 64 for Levofloxacin, respectively) [27].

\section{Conclusions and Recommendations:-}

The study suggests that nosocomial sepsis among neonates were still at high-frequency. The vast majority of $A$. baumannii isolates were multidrug resistant and harboring gyrA and parC resistance genes. Considerable efforts are needed for choosing antimicrobial drugs and combination therapy. Further studies are required for genotyping by sequencing of problematic resistant $A$. baumannii isolates in our hospitals.

\section{Ethical approval:-}

The present study was carried out with approval and agreement of Ethical and Medical Committee in College of Health \& Medical Technology/Baghdad.

\section{References:-}

1. Dijkshoorn L. , Alexandr Nemec \& Harald Seifert. An increasing threat in hospitals: multidrug-resistant Acinetobacter baumannii. Nat Rev Microbiol. 2007;5(12):939-51.

2. Ana Maria Gonzalez-Villoria1 and Veronica Valverde-Garduno. Antibiotic-Resistant Acinetobacter baumannii Increasing Success Remains a Challenge as a Nosocomial Pathogen. Journal of Pathogens, Volume 2016, Article ID 7318075, 10 pages.

3. Michalopoulos A, Falagas ME. Treatment of Acinetobacter infections. Expert Opin Pharmacother. 2010;11(5):779-788.

4. Antunes, LCS; Visca, P; Towner, KJ, GS. "Acinetobacter baumannii: evolution of a global pathogen". Pathogens and Disease. 2014; 71 (3): 292-301.

5. Vishal B Shete, Dnyaneshwari P Ghadage, Vrishali A Muley, and Arvind V Bhore. Acinetobacter Septicemia in Neonates Admitted to Intensive Care Units. J Lab Physicians. 2009; 1(2): 73-76.

6. Peleg AY, Seifert H, Paterson DL. Acinetobacter baumannii: emergence of a successful pathogen. Clin Microbiol Rev. 2008;21:538-82.

7. Rahal J. "Novel antibiotic combinations against infections with almost completely resistant Pseudomonas aeruginosa and Acinetobacter species". Clin Infect Dis. 2006; 43(2): S95-9.

8. Eraç B1, Yılmaz FF, Hoşgör Limoncu M, Oztürk I, Aydemir S. Investigation of the virulence factors of multidrug-resistant Acinetobacter baumannii isolates. Mikrobiyol Bul. 2014 Jan;48(1):70-81.

9. Michael J. McConnell, Luis Actis \& Jero nimo Pachon. Acinetobacter baumannii: human infections, factors contributing to pathogenesis and animal models. FEMS Microbiol Rev 37. 2013; 130-155. 
10. Frédéric Collin, Shantanu Karkare and Anthony Maxwell. Exploiting bacterial DNA gyrase as a drug target: current state and perspectives. Appl Microbiol Biotechnol. 2011; 92(3): 479-497.

11. Abdollah Ardebili, Abdolaziz Rastegar Lari, Maryam Beheshti, and Elnaz Rastegar Lari. Association between mutations in gyrA and parC genes of Acinetobacter baumannii clinical isolates and ciprofloxacin resistance. Iran J Basic Med Sci. 2015; 18(6): 623-626.

12. Horan TC, Gaynes RP. Surveillance of nosocomial infections. In: Hospital Epidemiology and Infection Control, $3^{\text {rd }}$ ed., Mayhall CG, editor. Philadelphia: Lippincott Williams \& Wilkins, 2004:1659-1702.

13. Klinger G, Levy I, Sirota L, et al. Epidemiology and risk factors for early onset sepsis among very-low-birth weight infants. Am J Obstet Gynecol. 2009; 201(1):38.e1-6.

14. A. O. Ajao, G. Robinson, M. S. Lee, T. D. Ranke, R. A. Venezia, J. P. Furuno, A. D. Harris, and J. K. Johnson. Comparison of culture media for detection of Acinetobacter baumannii in surveillance cultures of critically-ill patients. European Journal of Clinical Microbiology \& Infectious Diseases. 2011, 30:1425.

15. Clinical and Laboratory Standards Institute. Performance standards for antimicrobial susceptibility testing. Twenty-fifth informational supplement, M100-S25. Wayne, PA: Clinical Laboratory Standards Institute; 2016.

16. Shipra Srivastava, Vijai Singh, Vipin Kumar, Praveen Chandra Verma, Rajeev Srivastava, Vaishali Basu, Vijayta Gupta, and Anil Kumar Rawat. Identification of regulatory elements in 16S rRNA gene of Acinetobacter species isolated from water sample. Bioinformation. 2008; 3(4): 173-176.

17. Jordi Vila, Joaquim Ruiz, Pilar Gon I, Angeles Marcos, and Teresa Jimenez De Anta. Mutation in the gyrA Gene of Quinolone-Resistant Clinical Isolates of Acinetobacter baumannii. Antimicrobial agents and chemotherapy. 1995; 39 (5): 1201-1203.

18. Mohammad-Hossein Maleki; Farid Azizi Jalilian; Hatef Khayat; Maryam Mohammadi ; Fazel Pourahmad; Khairollah Asadollahi; Iraj Pakzad; Nourkhoda Sadeghifard; Setareh Soroush; Mohammad Emaneini; Morovat Taherikalani. Detection of Highly Ciprofloxacin Resistance Acinetobacter Baumannii Isolated from Patients with Burn Wound Infections in Presence and Absence of Efflux Pump Inhibitor. MAEDICA - a Journal of Clinical Medicine. 2014; 9(2): 162-167.

19. Magiorakos AP1, Srinivasan A, Carey RB, Carmeli Y, Falagas ME, Giske CG, Harbarth S, Hindler JF, Kahlmeter G, Olsson-Liljequist B, Paterson DL, Rice LB, Stelling J, Struelens MJ, Vatopoulos A, Weber JT, Monnet DL. Multidrug-resistant, extensively drug-resistant and pandrug-resistant bacteria: an international expert proposal for interim standard definitions for acquired resistance. Clin Microbiol Infect. 2012;18(3):26881.

20. Manar Al-lawama, Haytham Aljbour, Asma Tanash, and Eman Badran. Intravenous Colistin in the treatment of multidrug-resistant Acinetobacter in neonates. Ann Clin Microbiol Antimicrob. 2016; $15: 8$.

21. Doaa Mohammeda and Omnia S. El Seifi. Bacterial nosocomial infections in neonatal intensive care unit, Zagazig University Hospital, Egypt. Egyptian Pediatric Association Gazette. 2014; 62: 72-79.

22. Ann L Anderson-Berry. Neonatal Sepsis. Medscape, http://emedicine.medscape.com/ Updated: Dec 31, 2015.

23. Izeta SOFTIĆ, Husref TAHIROVIĆ, Fahrija SKOKIĆ, Nijaz TIHIĆ, Vincenzo DI CIOMMO, Cinzia AURITI. An outbreak of nosocomial infection with Acinetobacter baumannii in the neonatal intensive care unit of the Department of Paediatrics, University Clinical Centre Tuzla, Bosnia and Herzegovina. Paediatrics Today 2013;9(2):163-169.

24. Jamileh Nowroozi, Abbas Akhavan Sepahi, Lida Tahmasebinejad Kamarposhti, Roya Razavipour, and Flor Mazhar. Evaluation of Ciprofloxacin (gyrA, parC Genes) and Tetracycline (tetB Gene) Resistance in Nosocomial Acinetobacter baumannii Infections. Jundishapur J Microbiol. 2014; 7(2): e8976.

25. Güler G, Eraç B. Investigation of fluoroquinolone resistance mechanisms in clinical Acinetobacter baumannii isolates. Mikrobiyol Bul. 2016;50(2):278-86.

26. Kyungwon Lee, Dongeun Yong, Seok Hoon Jeong, and Yunsop. Multidrug-resistant Acinetobacter spp.: increasingly problematic nosocomial pathogens. Yonsei Med J. 2011; 52(6): 879-891.

27. Wayne A. Warner, Shan N. Kuang, Rina Hernandez, Melissa C. Chong, Peter J. Ewing, Jen Fleischer, Jia Meng, Sheena Chu, Dawn Terashita, L'Tanya English, Wangxue Chen, and H. Howard Xu. Molecular characterization and antimicrobial susceptibility of Acinetobacter baumannii isolates obtained from two hospital outbreaks in Los Angeles County, California, USA. BMC Infect Dis. 2016; 16: 194. 